\title{
АМФОЛИТНЫЕ ПОВЕРХНОСТНО-АКТИВНЫЕ ВЕЩЕСТВА *
}

\author{
(Представил О. Эйзен)
}

В основу данной работы положены результаты исследований синтеза амфолитных поверхностно-активных веществ (АмПАВ), проводимых в секторе поверхностно-активных веществ Института химии АН ЭССР, и результаты проработки библиографии по этому вопросу, насчитывающей свыше 1500 названий (подробнее см. [']).

В настоящее время в общем объеме мирового производства ПАВ доля АмПАВ составляет не более $0,5 \%$, а их стоимость превышает стоимость типичных ПАВ в 5-6 раз, тем не менее интерес к этой группе соединений стремительно растет. Этот интерес обусловлен большим разнообразием структур АмПАВ, рядом их специфическиіх свойств и многофункциональностью применения. Главные достоинства АмПАВ связаны с биологическоой активностью, диспергирующей, комплексообразующей, гомогенизирующей и совмещающей способностями в отношении почти всех органических и неорганических компонентов, применяемых в чистящих, моющих, косметических и т. д. составах.

Несмотря на то, что АмПАВ имеют много преимуществ перед типичными анионными ПАВ, прогнозировать их столь широкое распространение, какое получили последние, нельзя. Сдерживающими факторами здесь являются многоэтапность синтеза АмПАВ и высокая стоимость ингредиентов.

АмПАВ принадлежит будущее в областях, где они проявляют присущие им специфические положительные свойства и где эффект от их применения по экономическим или экологическим соображениям себя оправдывает. Например, доля АмПАВ в косметической промышленности США превышает уже $30 \%$.

Благодаря упомянутым свойствам АмПАВ, их синергизму с ПАВ общего назначения и совмещающей способности можно ожидать, что создание композиций с другими, дешевыми ПАВ станет в будущем основным направлением применения АмПАВ. К примеру, такими композициями будут бесфосфатные моющие средства, детские шампуни, косметические средства и т. д.

B общем виде АмПАВ могут быть представлены формулой<smiles></smiles>

В их молекулах имеются гидрофобный радикал $\mathrm{C}_{9}-\mathrm{C}_{19}$ и гидрофильная часть, содержащая в простейшем случае одну группу, способную быть акцептором протона (основную группу, $\left.B^{+}\right)$и приобретать в результате положительный заряд, и протонодонорную группу (кислотную группу, $\left.A^{-}\right)$, которая в результате диссоциации может заряжаться отрицательно. В изоэлектрическом диапазоне.молекулы АмПАВ пред-

* Текст доклада на VI Всесоюзной конференции по поверхностно-активным веществам в Волгодонске, сентябрь 1984 г. 
ставляют собой диполярные ионы (цвиттер-ионы) или же нейтральные молекулы, так что ионизационная схема для АмПАВ тождественна схеме для простых амфолитов:

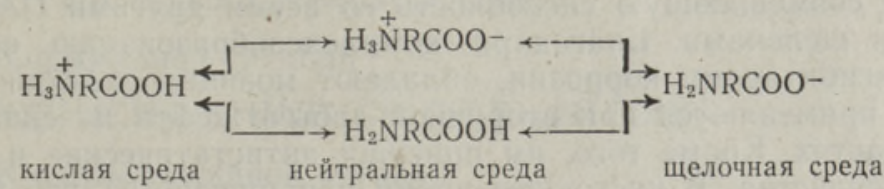

В зависимости от структуры амфолита отщепление протона от полностью протонизированного амфолита происходит через цвиттер-ион или через молекулярный ион молекулы.

- Сравнение АмПАВ в цвиттер-ионной форме с неионогенными ПАВ неправомерно, так как общий заряд молекулы остается высоким, а у неионогенных ПАВ он отсутствует.

В роли катионной группы обычно выступают первичная, вторичная или третичная аминогруппы (с возможностью замены азота серой, фосфором, мышьяком и т. д.), а в роли анионной группы - карбоксильная, сульфонатная, сульфоэфирная и фосфоркислотные группы.

Дискуссионным остается перечень ПАВ, которые относятся к АмПАВ. Ориентировочно можно нспользовать постулаты, выдвинутые в $\left[{ }^{2}\right]$, где к АмПАВ (с одной кислотной и одной основной группами) причисляют вещества в зависимости от их кислотных и основных констант диссоциации $\left(K_{a}\right.$ и $\left.K_{b}\right)$ :

1. Вещество является амфолитом, если величины констант ионизации кислотной и основной групп относительно низкие и не слишком различающиеся по величине, например: $K_{a} \simeq K_{b} \simeq 10^{-3}-10^{-7}$.

2. Вещество не является амфолитом, если значения обеих констант высокие.

3. Вещество не является амфолитом, если одна константа значительно больше другой.

Ряд соединений, которые традиционно считают АмПАВ, не могут быть отнесены в этот класс ПАВ, так как они не способны выступать в качестве донора или акцептора протона. В частности, алкилбетаины (напр., $\mathrm{RN}^{+}\left(\mathrm{CH}_{3}\right)_{2} \mathrm{CH}_{2} \mathrm{COO}^{-}$) не могут отдавать протон основанию и выступать как кислоты. В то же время алкиламиносульфонаты (напр., $\mathrm{RNHC}_{2} \mathrm{H}_{4} \mathrm{SO}_{3} \mathrm{H}$ ) выступают как анионные ПАВ, так как их катионңая форма не реализуется вследствие высокой кислотности сульфокислотной группы.

Учитывая изложенное выше, АмПАВ можно классифицировать как класс цвиттер-ионных ПАВ (ЦПАВ), где алкилбетаины и алкиламиносульфонаты (сульфаты, фосфаты) являются предельными структурами. Положение усложняется, естественно, при наличии нескольких основных групп и промежуточных функциональных групп. Поэтому общий класс ЦПАВ можно разделить на три группы:

1. Катионно-ориентированные ЦПАВ (напр., алкилбетаины).

2. Анионно-ориентированные ЦПАВ (напр., алкиламиносульфонаты).

3. Истинно амфолитные ЦПАВ (алкиламинокарбоновые кислоты, алкиламинофенолы, алкилимидазолины).

При внутригрупповой классификации ПАВ ориентиром служат структурные различия, т. е. химическое строение. По этому принципу и по некоторому сходству в поведении АмПАВ можно разделить на пять основных групп: 1) алкиламинокарбоновые-кислоты; 2) алкилбетанны; 3) алкилимидазолиновые ПАВ; 4) алкиламиноалкансульфонаты, -сульфаты и т. д.; 5) полимерные АмПАВ. 


\section{Алкиламинокарбоновые кислоты (ААКК)}

Большинство ААКК проявляет наряду с высокими технологическими свойствами совмещающую способность со всеми другими ПАВ, электролитами и щелочами. Благодаря комплексообразованию они могут служить ингибиторами коррозии, обладают моющим действием в морской воде, применяются при вторичной добыче нефти из скважин и в других областях. Кроме того, им присущи антистатические и дезинфицирующие свойства. В настоящее время обнаружено $\left[{ }^{3}\right]$, что последние обусловлены гидрохлоридными солями остатков алкиламинов и алкилполиаминов, применяемых при синтезе ААКК. Свойства ААКК сильно зависят от рН среды. Так, в сильнокислой среде они становятся катионными ПАВ и действуют в этих условиях как смягчители, проявляя к тому же бактерицидные свойства. В нейтральной и слабощелочной средах повышается эффективность очистки и пенообразования.

Изоэлектрическая точка алкиламинокарбоновых кислот определяется как центр широкой зоны величин $\mathrm{pH}$, где амфолит практически полностью выступает в форме цвиттер-иона, например, $\mathrm{RN}+\mathrm{H}_{2} \mathrm{C}_{2} \mathrm{H}_{4} \mathrm{COO}$ Так, для $\mathrm{N}$-додецил- $\beta$-аланина в диапазоне $\mathrm{pH} 4,3-7,7$ около $98 \%$ молекул находятся в диполярной форме. Катионактивные свойства этого вещества проявляются полностью при $\mathrm{pH}$ около 2, а анионактивные при рН около 11.

В зависимости от присутствия в молекуле ААКК различных функциональных групп существующие АмПАВ этого типа можно условно разделить на десять подклассов.

1. Простейшие ААКК. Они могут быть представлены общей формулой

$$
\mathrm{RNH}\left(\mathrm{CH}_{2}\right)_{n} \mathrm{COOH} \text {. }
$$

Алкильный радикал амина обычно прямоцепочечный, а короткая углеводородная цепь между аминной группой и карбоксильной иногда имеет разветвленный характер

\section{$\mathrm{RNHCH}\left(\mathrm{CH}_{3}\right) \mathrm{CH}_{2} \mathrm{COOH}$.}

2. Алкиламинофенилкарбоновые кислоты

$$
\mathrm{RNH}-\mathrm{C}_{6} \mathrm{H}_{4}-\mathrm{COOH} .
$$

3. ААКК с первичной, вторичной и третичной аминогруппами

$\mathrm{RN}\left(\mathrm{CH}_{3}\right) \mathrm{CH}_{2} \mathrm{COOH}$,

$\mathrm{RCH}\left(\mathrm{NH}_{2}\right) \mathrm{COOH}$,

$\mathrm{RCH}$ (NHR) $\mathrm{COOH}$.

4. АAKК с гидроксильной группой

$\mathrm{RCH}(\mathrm{OH}) \mathrm{CH}_{2} \mathrm{NHCH}\left(\mathrm{CH}_{3}\right) \mathrm{COOH}$, $\mathrm{RCH}(\mathrm{OH}) \mathrm{CH}_{2} \mathrm{~N}\left(\mathrm{CH}_{3}\right)\left(\mathrm{CH}_{2}\right)_{n} \mathrm{COOH}$, $\mathrm{CH}_{3}\left(\mathrm{CH}_{2}\right)_{7} \mathrm{CH}(\mathrm{OH}) \mathrm{CH}\left(\mathrm{NR}^{1} \mathrm{R}^{2}\right)\left(\mathrm{CH}_{2}\right)_{7} \mathrm{COOH}$.

5. АAKK с эфирной группой

$\mathrm{ROCH}_{2} \mathrm{CH}_{2} \mathrm{NHCH}_{2} \mathrm{CH}_{2} \mathrm{COOH}$, $\mathrm{ROCH}_{2} \mathrm{CH}_{2} \mathrm{~N}\left(\mathrm{CH}_{3}\right) \mathrm{CH}_{2} \mathrm{COOH}$, $\mathrm{ROCH}_{2} \mathrm{CH}_{2} \mathrm{CH}_{2} \mathrm{NHCH}\left(\mathrm{CH}_{3}\right) \mathrm{CH}_{2} \mathrm{COOH}$, $\mathrm{RNHCH}_{2} \mathrm{CH}_{2} \mathrm{OCH}_{2} \mathrm{CH}_{2} \mathrm{COOH}$. 
6. ААКК со сложноэфирной группой

$\mathrm{ROOCCH}_{2} \mathrm{CH}_{2} \mathrm{NH}\left(\mathrm{CH}_{2}\right)_{n} \mathrm{COONa}$, $\mathrm{RNHCH}_{2} \mathrm{CH}_{2} \mathrm{OOCCH}=\mathrm{CHCOOMe}$.

7. ААКК с амидной группой

$\mathrm{RCONH}\left(\mathrm{CH}_{2}\right)_{4} \mathrm{CH}\left[\mathrm{NH}\left(\mathrm{CH}_{2} \mathrm{CH}_{2} \mathrm{O}\right)_{n} \mathrm{H}\right] \mathrm{COOH}$.

8. ААКК с сульфамидной группой

$\mathrm{RSO}_{2} \mathrm{NHCH}_{2} \mathrm{~N}\left(\mathrm{CH}_{3}\right) \mathrm{CH}_{2} \mathrm{COOH}$.

9. Вещества с двумя и более аминогруппами и амидогруппами

$\mathrm{RNHCH}_{2} \mathrm{CH}_{2} \mathrm{NHCH}\left(\mathrm{R}^{1}\right) \mathrm{CH}\left(\mathrm{R}^{2}\right) \mathrm{COOH}$,

$\mathrm{RNH}\left(\mathrm{CH}_{2}\right)_{3} \mathrm{~N}\left(\mathrm{CH}_{3}\right)\left(\mathrm{CH}_{2}\right)_{3} \mathrm{NHCH}(\mathrm{COOH}) \mathrm{CH}_{2} \mathrm{CONH}_{2}$,

$\mathrm{RNHCH}(\mathrm{COONa}) \mathrm{CH}_{2} \mathrm{CONH}\left(\mathrm{CH}_{2}\right) \mathrm{N} \overbrace{\mathrm{R}^{3}}^{\mathrm{R}^{2}}$.

10. Вещества с несколькими гидроксильными и аминными группами

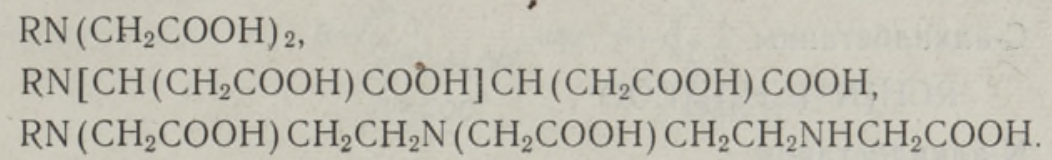

\section{Алкилбетаины (АБ)}

АБ получили свое название от бетаина $\left(\mathrm{CH}_{3}\right)_{3} \mathrm{~N}^{+} \mathrm{CH}_{2} \mathrm{COO}^{-}$, обнаруженного более 100 лет назад в соке сахарной свеклы (Beta vulgaris). Позднее все родственные соединения с четвертичной аммониевой группой и одним кислотным остатком стали называться бетаинами.

Молекула АБ выступает как цвиттер-ион в широкой зоне величин $\mathrm{pH}$. Это катионно-ориентированное ЦПАВ, так как его четвертичноалкилзамещенная аммониевая (или фосфониевая и др.) группа не способна при добавлении щелочи превращаться в незаряженную аминогруппу. Поэтому его щелочные соли неизвестны. Присоединением кислоты ионизация кислотной группы $\left(-\mathrm{COO}^{-}\right)$может быть подавлена. Кислотные соли, как катионная форма АБ, известны.

АБ начиная с $\mathrm{C}_{8}$ широко используются за рубежом в качестве биологически мягких ПАВ в шампунях, в косметических препаратах, в моющих средствах общего назначения и т. д. К бетаинам относятся и природные вещества, такие как $\alpha$-лецитин, нарцеин, ацилкарнитины и др., широко распространенные в животном и растительном мире.

В отличие от других АмПАВ, АБ растворяются в широком интервале $\mathrm{pH}$. Наличие четвертичного атома азота обусловливает их бактерицидное действие, поэтому их можно считать наиболее близкими к катионным ПАВ или даже переходным классом от амфолитных к катионным ПАВ.

Отличительными особенностями АБ являются: диспергирование кальциевых мыл, накипей, осадков и красок; высокая совместимость с неорганическими соединениями; ингибирование коррозии; дезинфицирующие свойства. Применяются в средствах для мойки в холодной и в высокожесткой воде, в гальванотехнике, в производстве суперфосфата и во многих других экстремальных условиях. В этом отношении выделяются сульфобетаины, превосходящие по многим свойствам обычные АБ. Свойства сульфобетаинов и аналогичных им ПАВ 
мало зависят от температуры, рН среды и от ионной силы раствора. В результате электронейтральности их щвиттер-ионная структура сохраняется по всей длине шкалы величин $\mathrm{pH}$, они не проводят электрический ток, не изменяют электрофоретической подвижности белков и не взаимодействуют с ионообменными смолами. По этим причинам и по инертности в отношении белков они нашли применение в биохимии как солюбилизаторы при их разделении и очистке.

Амидобетаины, благодаря мягкому действию, которое они оказывают на кожу и волосы, а также дезинфицирующему и антистатическому эффекту, нашли широкое применение в косметике, особенно в производстве шампуней.

Изоэлектрические точки для октил-, децил- и додецилбетаинов находятся при $\mathrm{pH}=5,6,10$ и 6,65 соответственно. При более низких $\mathrm{pH}$ АБ перемещаются к катоду.

Фотометрическим изучением установлено, что в разбавленных растворах АБ существуют в виде сферических мицелл с радиусом, равным длине одной молекулы ПАВ, причем эти мицеллы не взаимодействуют между собой в воде или в растворе $\mathrm{NaCl}$.

По методам синтеза АБ можно разделить на 5 основных групп.

1. Алкилбетаины:

a) С-алкилбетаины

$$
\mathrm{RCH}\left[\mathrm{N}^{+}\left(\mathrm{CH}_{3}\right)_{3}\right] \mathrm{COO}^{-} \text {, }
$$

б) $\mathrm{N}$-алкилбетаины

$$
\mathrm{RN}^{+}\left(\mathrm{CH}_{3}\right)_{2} \mathrm{CH}_{2} \mathrm{COO}^{-} \text {. }
$$

Гидрофобный радикал может быть алифатического или алифатическо-ароматического характера, часто он содержит гидроксильную группу. Метильные группы могут быть заменены этильными или пропильными, но это вызывает затруднения при бетаинизации, которая обычно проводится хлоруксусной кислотой.

2. Сульфит, сульфо-, сульфат- и фосфатбетаины:

$$
\begin{gathered}
\mathrm{RN}^{+}\left(\mathrm{CH}_{3}\right)_{2} \mathrm{CH}_{2} \mathrm{CH}_{2} \mathrm{OSO}_{2}^{-}, \\
\mathrm{RN}^{+}\left(\mathrm{CH}_{3}\right)_{2} \mathrm{CH}_{2} \mathrm{CH}_{2} \mathrm{SO}_{3}^{-}, \\
\mathrm{RC}_{6} \mathrm{H}_{4} \mathrm{CH}_{2} \mathrm{~N}^{+}\left(\mathrm{CH}_{3}\right)_{2} \mathrm{CH}_{3} \mathrm{CH}_{2} \mathrm{OSO}_{3}^{-}, \\
\mathrm{RN}^{+}\left(\mathrm{CH}_{3}\right)_{2} \mathrm{CH}_{2} \mathrm{CH}(\mathrm{OH}) \mathrm{CH}_{2} \mathrm{OP}(\mathrm{OH})(\mathrm{O}) \mathrm{O}^{-}
\end{gathered}
$$

3. Амидобетаины

$$
\mathrm{RCONH}\left(\mathrm{CH}_{2}\right)_{3} \mathrm{~N}^{+}\left(\mathrm{CH}_{3}\right)_{2} \mathrm{CH}_{2} \mathrm{COO}^{-} \text {. }
$$

4. Оксиэтилированные бетаины

$$
\mathrm{RN}^{+}\left[\left(\mathrm{CH}_{2} \mathrm{CH}_{2} \mathrm{O}\right)_{p} \mathrm{H}\right]\left[\left(\mathrm{CH}_{2} \mathrm{CH}_{2} \mathrm{O}\right)_{q} \mathrm{H}^{-} \mathrm{CH}_{2} \mathrm{COO}^{-}\right. \text {. }
$$

5. Другие цвиттер-ионные ПАВ:

$$
\begin{aligned}
& \mathrm{RCON}^{-}-\mathrm{N}^{+}\left(\mathrm{CH}_{3}\right)_{3}, \\
& \text { RNHC }\left(=\mathrm{N}^{+} \mathrm{H}_{2}\right) \mathrm{OCH}_{2} \mathrm{CH}_{2} \mathrm{CH}_{2} \mathrm{SO}_{3}^{-},
\end{aligned}
$$

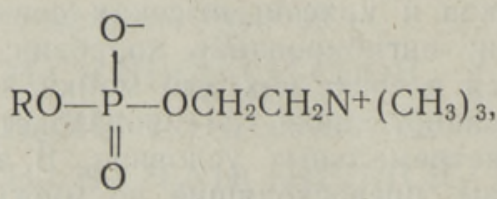

$\mathrm{RN}^{+}\left(\mathrm{CH}_{3}\right)_{2}\left(\mathrm{CH}_{2}\right)_{n} \mathrm{CONHO}^{-}$. 
Основным сырьем для получения АБ служат вторичные и третичные амины и жирные кислоты. Реже используются алкилбензилхлориды, алкилпиридины, алкилсультоны, $\omega$-галоидозамещенные жирные кислоты, первичные амины и спирты.

\section{Производные алкилимидазолинов (ИмАмПАВ)}

Хотя в последнее время показано, что структура многих выпускаемых ИмАмПАВ не циклическая, а линейная, тем не менее им присущи высокие технологические свойства. Кроме того, они отличаются антистатическими, бактерицидными, смягчающими эффектами и совместимостью - с мылом и другими ПАВ.

Благодаря низкой токсичности и полному отсутствию раздражающего действия ИмАмПАВ широко применяются для изготовления детских шампуней, особенно в Англии и США.

Наиболее характерной структурой ИмАмПАВ является такая, в которой анионные и катионные группы приблизительно равносильны:

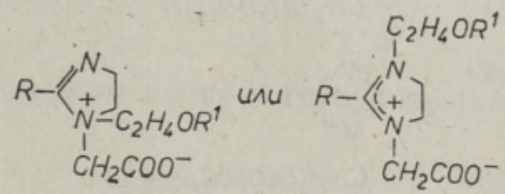

где $\mathrm{R}$ - углеводородный радикал $\mathrm{C}_{7}-\mathrm{C}_{17}, \mathrm{R}^{1}-\mathrm{H}, \mathrm{Na}, \mathrm{CH}_{2} \mathrm{COOMe}$.

Сбалансированность ионизирующих групп обеспечивает этим соединениям хорошие санитарно-гигиенические и технологические свойства.

ИмАмПАВ являются производными 4,5-дигидро-1,3-диазола или 4,5-дигидроимидазола

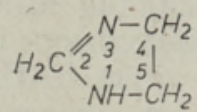

По структуре и методам синтеза их можно разделить на два основных класса - небетаинные и бетаинные, каждый из которых включает соединения карбоксилатного и сульфо- или сульфоэфирного характера.

1А. -Карбоксинебетаинные ИмАмПАВ:

a)<smiles>[R]C1=NCCN1CC(=O)OC</smiles>

б)<smiles>[R]C1NCCN1CCNCC(=O)O</smiles>

B)

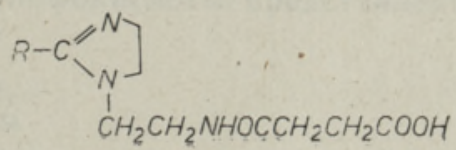


1Б. Сульфо- и сульфатнебетаинные ИмАмПАВ:

a)

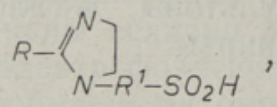

ס)

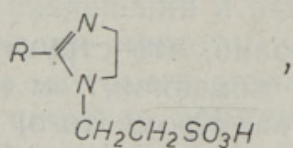

b)

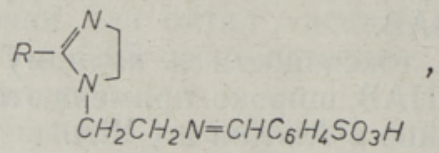

2)

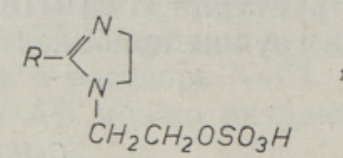

g)

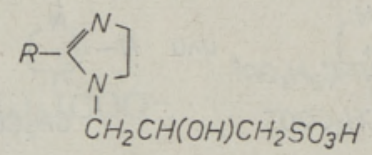

2A. Карбоксибетаинные ИмАмПАВ:

a)

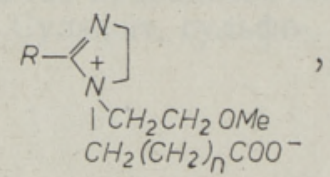

б)

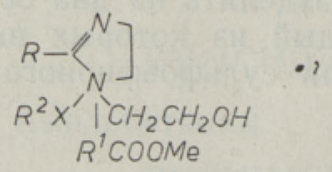

где $\mathrm{R}^{2} \mathrm{X}-\mathrm{OH}^{-}$, или

$\mathrm{C}_{12} \mathrm{H}_{25} \mathrm{OSO}_{3}^{-}$, или $\mathrm{C}_{11} \mathrm{H}_{23} \mathrm{CON}\left(\mathrm{C}_{2} \mathrm{H}_{4} \mathrm{OH}\right) \mathrm{C}_{2} \mathrm{H}_{4} \mathrm{OSO}_{3}^{-}$ и т. д.
2Б. Сульфо- и сульфатбетаинные ИмАмПАВ:

a)

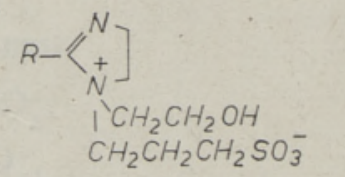

б)

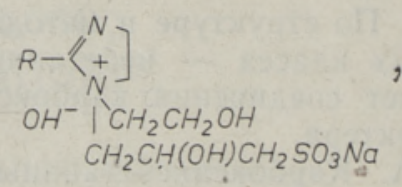

B)

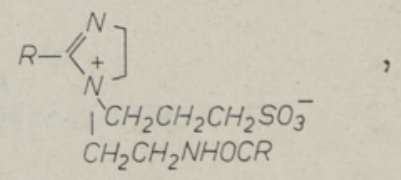

2)

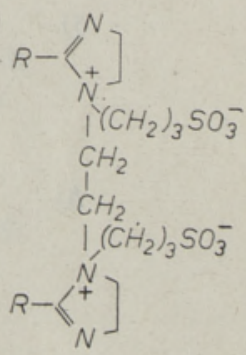


ИмАмПАВ применяются для изготовления шампуней, как антистатики и ингибиторы коррозии. Они являются смягчителями текстильных материалов, чистящими и моющими средствами.

\section{Алкиламиноалкансульфонаты, -сульфаты \\ $\left(\mathrm{AAAC}_{1}\right.$ и $\mathrm{AAAC}_{2}$ соответственно и т. д.)}

В зависимости от кислотных и основных групп, их количества и констант ионизации эти вещества можно разделить на пять основных групп.

1. Соли $\mathrm{AAAC}_{1}$

$$
\text { , } \mathrm{RN}\left(\mathrm{R}^{1}\right) \mathrm{R}^{2} \mathrm{SO}_{3} \mathrm{Me} \text {. }
$$

2. Соли $\mathrm{AAAC}_{2}$

$$
\mathrm{RN}\left(\mathrm{R}^{1}\right) \mathrm{R}^{2} \mathrm{OSO}_{3} \mathrm{Me} .
$$

3. Производные ароматических аминосульфокислот<smiles>[R19]S(=O)(=O)O[Na]</smiles>

4. Аминосульфонаты с атомом азота в гетероциклах<smiles>[R]OS(=O)(=O)OCCO</smiles>

5. Другие аминосоединения (фосфаты, фосфонаты и т. д.)

$$
\begin{aligned}
& \mathrm{RN}\left(\mathrm{R}^{1}\right) \mathrm{R}^{2} \mathrm{P}(\mathrm{O})(\mathrm{OH})_{2}, \\
& \mathrm{RN}\left(\mathrm{R}^{1}\right) \mathrm{R}^{2} \mathrm{OP}(\mathrm{O})(\mathrm{OH})_{2},
\end{aligned}
$$

где $\mathrm{R}$ - длинный углеводородный радикал, $\mathrm{R}^{1}$ - короткий углеводородный радикал, $\mathrm{R}^{2}$ - короткий двухвалентный радикал.

Анионно-ориентированные ЦПАВ легко переходят в цвиттер-ионную форму, что позволяет легко выделять их в чистом виде. Константа ионизации кислотной группы гораздо больше, чем основной. Однако в случае нескольких основных групп и при наличии рядом с кислотной группой других гидрофильных групп (гидроксильной, эфирной и т.д.) они по свойствам и областям применения приближаются $\mathrm{k}$ АмПАВ. Хотя в кислых средах в катионную форму эти ЦПАВ не переходят, они все же обладают некоторыми бактерицидными свойствами.

Основными представителями $\mathrm{AAAC}_{1}$ являются производные 2-аминоэтансульфокислоты (таураты). В Институте химии АН ӘССР синтезировано много веществ этого типа, в том числе таких, у которых водород при азоте заменен различными функциональными группами. Они могут применяться в косметических препаратах, в композициях для мытья посуды, как смачиватели при изготовлении кинофотоматериалов, как ингибиторы коррозии и т.д. Они обладают хорошей способностью диспергировать кальциевые мыла и устойчивостью к солям жесткости воды. Их растворимость обеспечивает наличие в молекуле дополнительных гидрофильных групп.

Ароматические аминосульфокислоты представлены меньшим числом производных. Их формула

$$
\mathrm{R}-\underset{\mathrm{R}^{1}}{\mathrm{~N}}-\mathrm{ArSO}_{3} \mathrm{Me},
$$


где $\mathrm{Ar}$ - ароматический или алифатно-ароматический двухвалентный радикал, R и $\mathrm{R}^{1}$ - алифатические радикалы.

$\mathrm{K}$ ним относятся также вещества с гидразидной группой

\section{RCONHNHArSO${ }_{3} \mathrm{Me}$.}

$\mathrm{N}$-Бензил- и $\mathrm{N}$-дибензилсульфаниловые кислоты и их соли, а также сульфонированные фенилгидразиды жирных кислот производятся за рубежом в промышленном масштабе.

Известно также значительное число ЦПАВ с основным азотом и сульфогруппой, не являющихся $\mathrm{N}$-алкилпроизводными низкомолекулярных аминоалкан- или аминоарилсульфокислот. Они имеют различное строение - с атомом азота в пеервичном, вторичном или третичном положении, с сульфогруппой в конце гидрофобной цепи или в середине ее и т. п. Например,<smiles>[R][R](C([R])N)N([R])[R]</smiles>

$\mathrm{K}$ аминосульфонатам с атомом азота в гетероциклах относятся производные имидазолинов. Кроме них, имеют значение производные ароматических 1,2-диаминов. Например, 2-замещенные бензимидазолы

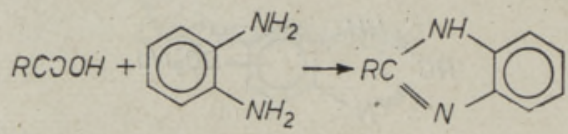

Встречаются 2-замещенные индолы<smiles>[R]=Cc1ccccc1N</smiles>

и 2 -алкил-4,6-диамино-1,3,5-триазины<smiles></smiles>

Аминосульфаты менее распространены, чем их аналоги с сульфогруппой. Они представлены в основном двумя типами.

1. Сульфаты низкомолекулярных аминоспиртов, замещенные длинным алкильным радикалом<smiles>[R]N([R])[R]OS(C)(=O)=O</smiles>

2. Сульфаты ненасыщенных или гидроксилсодержащих длинноцепочечных аминов<smiles>[R]C([R]O[Na])CCCCCC([R])O[Na]</smiles> 
где $\mathrm{R}$ - длинноцепочечный радикал, a $\mathrm{R}^{1}$ и $\mathrm{R}^{2}$ - короткие алкильные радикалы или водород.

Эти вещества имеют промышленное значение и выпускаются различными фирмами под названиями «Duponol», «Sulframin», «Detergent $\mathrm{D}$ » и т. д. Они применяются в текстильной промышленности и при изготовлении кинофотоматериалов.

Представляют интерес вещества, в которых в качестве основной группы применяется амин или его производные, а в качестве кислотной - производные фосфорных кислот. Как и их аналоги с амидной группой, они в основном являются неполными эфирами ортофосфорной кислоты или алкилфосфоновых кислот.

Специфические свойства этих ПАВ позволяют надеяться, что они найдут применение. Они обладают бактерицидным действием и, в зависимости от длины алкильного радикала, могут быть эмульгаторами или смачивателями.

\section{Полимерные АмПАВ (ПАмПАВ)}

Из-за отсутствия достаточных литературных данных невозможно, к сожалению, составить детальную классификацию ПАмПАВ не только по структуре, но и по свойствам. Разделим их пока на три основные группы:

1. Природные, к которым относятся белки, протеины, нуклеиновые кислоты и т. д.

2. Модифицированные природные. Сюда можно отнести

а) олигомерные гидролизаты белковых веществ,

б) сульфатированный хитин,

в) продукты последовательной ступенчатой конденсации аминов, формальдегида, альбумина и жирных кислот.

г) производные целлюлозы, полученные введением карбоксильных и диэтаноламиноэтильных групп.

3. Синтетические. В их молекулах могут сочетаться структурные признаки всех приведенных выше классов АмПАВ. Приведем наиболее распространенные синтетические ПАмПАВ:

a)<smiles>CCC(C)c1cc[n+](CC)cc1</smiles>

б)<smiles>CCC(CC(C)C(N)=O)C(=O)N[C@H](C)CCC(=O)[O-]</smiles> 
B)<smiles>CCC(C)C[NH+](C)CC(=O)OC</smiles>

г)<smiles>[R20]C(=O)OCCN(C)CC</smiles>

д)

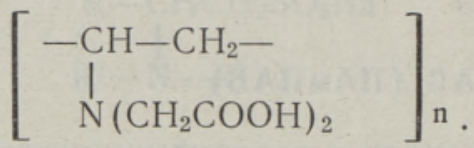

Полимерные АмПАВ применяются как антистатики, дезинфицирующие агенты, диспергаторы, эмульгаторы и т.д. Весьма интересным направлением является применение ПАмПАВ для разделения сложных смесей электролитов и в химиотерапии.

\section{ЛИТЕ РА Т У РА}

1. Файнгольд С., Кууск $A$., Киик $X$. Химия анионных и амфолитных азотсодержащих ПАВ. Таллин, 1984.

2. Moore, C. D., Hardwick, R. S. Ampholyfic surface active agents. - Chem. Ind., 1963 , N 8, 1268-1269.

3. Лиманов В. Е., Иванов С. Б., Сукласян А. Н., Скворцова Е. К. Синтез и антимикробная активность соединений, полученных из высших алкиламинов. Хим.-фарм. ж., 1980, 14, № 5, 23-26.

Институт химии

Академии наук Эстонской ССР
Поступила в редакцию $29 /$ X 1984

S. FAINGOLD, A. KUUSK

\section{AMFOLUUTSED PINDAKTIIVSED AINED}

On esitatud ülevaade enamlevinud amfolüütsete pindaktiivsete ainete tüüpidest ja nende omadustest.

S. FAINGOLD, A. KUUSK

\section{AMPHOLYTIC SURFACE ACTIVE AGENTS}

The most widespread types of ampholytic surfactants and their properties are reviewed. 